\title{
Ethics in Oncology. Stormy Weather Ahead, but also the Promise of a Better World?
}

This issue of ONKOLOGIE focuses on Ethics in Oncology - a topic that has recently received much attention - for very good reasons, we believe. Technical advances in medicine have generated formerly unexpected opportunities to treat cancer patients and to prolong or even safe the lives of many. For many cancers we are now in a situation where we can choose between a great spectrum of different treatments and more often than not making a 'best' choice is becoming increasingly difficult. Supportive care that renders cancer treatment more tolerable has come into focus and has become of almost equal importance to the cancer treatment itself. But what are the 'soft issues' for patients and health professionals? Patients certainly expect more from their caregivers than just knowledge and skills, more than just the technical delivery of expert cancer treatment: they need to talk and they need to trust.

The social prestige of physicians in Germany is still surpassing by far the ones of all other professions according to a 2003 survey of the renowned Allensbach Institute. Among the reasons for this extraordinary finding are certainly the high moral standards that are assigned to physicians, their dedication to act in the best interest of their patients as well as their professional altruism. Although not substantiated by survey data, we assume that within the medical profession oncologists even score highest in these virtues. - At least we think they should do. However, the formidable record of the medical profession is in jeopardy. Since 1966 when the same kind of survey was performed for the first time, the excellent grades that are given to the medical profession continue to drop. In this issue of ONKOLOGIE two critical topics are being addressed that have received great attention in Anglo-American countries, but - in our opinion - are still being neglected in Germany. One important issue is maintaining the independence of the medical profession from the temptations of money and pride. As 'health' is predicted to become more and more one of the leading 'industries' in the forthcoming years, physicians as the gatekeepers of public health-care are very likely to become the prime targets for tough promotional efforts of the various actors that try to make business on the expanding 'health market'. Indeed, even today many practicing oncologists see themselves torn between the public expectation of responsible spending of limited health-care resources and the expectation of individual patients to benefit from all recent - and almost inevitably highly expensive - innovations that have come about in oncology. Industry will surely interact in this conflict to their best profit. However, as Hildebrandt and Ludwig [1] point out in their contribution in this issue of ONKOLOGIE a partnership between the medical profession and industrial sponsors can be beneficial for all parties involved - physicians, patients, the public, and industrial sponsors alike - if all interests are openly declared and balanced and if a strict set of rules are followed that serve as a framework for such cooperations.

Another issue touching the reputation of our profession has come into focus by a report from the Institute of Medicine (IOM) of the National Academies of the United States (US) that had been issued in September 1999, claiming that far more than 40,000 preventable deaths occur each year in the US due to medical errors. Comparable epidemiologic figures are lacking for Germany. However, almost every practicing oncologist knows very well about medical errors or near-errors having occurred in his own practice or his immediate practice environment. Although the estimated number of undetected cases is high and many events will go unnoticed, particularly in oncology, medical errors cause significant morbidity and even mortality. Preventable suffering from medical errors is tragic for patients, relatives, and doctors alike. When everyone is giving his best to fight cancer, one can imagine the devastating feelings when the struggle did more harm than good. Individual as well as public trust in the medical profes-

\begin{tabular}{ll}
\hline KARGER & @ 2003 S. Karger GmbH, Freiburg \\
Fax +497614520714 & Accessible online at: \\
$\begin{array}{l}\text { E-mail Information@Karger.de } \\
\text { www.karger.com }\end{array}$ & www.karger.com/onk
\end{tabular}


sion is clearly lost when preventable medical errors become apparent. - It is hardly reassuring that Hansis [2] finds in reviewing recent literature that medical errors in oncology rarely lead to litigations.

Medical errors can come about in many forms and may result not only from individual failure to deliver appropriate care but even more often from organizational shortcomings. In his contribution, Thomeczek [3] analyzes some of the factors that lead to medical errors and makes a strong argument in favor of prospective error management to reduce the incidence as well as the consequences of medical errors. In his opinion many lessons can be learned from other professions that share similarly complex working environments, such as aviation, that have effectively introduced prospective error management strategies already years ago. In the field of error management medicine obviously does not seem to be at the forefront of the technical development, and may have to close up to a better performance. As medication errors are among the most frequent medical errors in oncology Müller [4] in his contribution tries to identify strategies to tackle the problem of erroneous medication and demonstrates that even small changes in organizing clinical workflow may result in substantial error reduction.

Both authors come to the similar conclusion that changing our attitudes toward medical errors will be the first step in improving the quality of our work. Humans inevitably make mistakes no matter how hard they try to avoid them. We should therefore no longer consider medical errors solely as individual incompetence, but rather as system failures which need to be analyzed in a non-punitive way in order to prevent errors occurring in the first place and thus to deliver safer care. Yet, many other aspects in dealing with medical errors have not been addressed. Which is the best way to handle medical errors, once they have occurred? Should the truth be disclosed to a patient or his relatives, even when the error did not result in harm? And if yes, to what extent should such information be given? If a patient died because of a medical error, should the relatives be told about this? After a serious medical error has happened what kind of support does a patient, the relatives and, very importantly, the involved medical staff need, who might all have suffered one of the worst experience of their lives? We all have given little attention to these problems in the past, but as medical errors are here to stay, we believe we should better catch up in doing so.

Hansis correctly points out in his contribution that adherence to evidence-based practice guidelines that have become broadly available in oncology are the best safeguard against medical errors. Very few would argue against this statement. Yet, it is within the intricacies of medical ethics that the very information on which evidence-based medicine relies - randomized clinical trials - is not without ethical dilemmas either. Meran [5] addresses some of these in his contribution, rounding off this issue of ONKOLOGIE on medical ethics. We know that there are many other topics to be covered and hope that other issues on medical ethics will follow.

Jörg Beyer, Marburg

Andreas Frewer, Hannover Johannes Gobertus Meran, Wien

\section{References}

1 Hildebrandt M, Ludwig WD: Clinical research and industrial sponsoring: Avenues towards transparency and credibility. Onkologie 2003:26:529-534.

2 Hansis ML: Malpractice in oncology. Onkologie 2003;26:535-538.

3 Thomeczek C: Error prevention and error management in medicine - adopting strategies from other professions. Onkologie 2003;26:545-550.

4 Müller T: Typical medication errors in oncology: Analysis and prevention strategies. Onkologie 2003;26:539-544.

5 Meran JG: Consent and equipoise, the crucial ethical issues in randomised clinical trials. Onkologie 2003;26:524-528. 